\title{
Multifocal Choroiditis Complications (CNV) Treatment: A Case Report
}

\author{
Nadon QAFA. \\ ${ }^{1}$ Department of Ophthalmology, American Hospital of Tirana, Albania
}

\begin{abstract}
Background: Multifocal choroiditis is a condition characterized by intraocular inflammation and multifocal choroidal lesions occurring in the absence of any known ocular or systemic disease. Cystoid macular edema, subretinal fibrosis, and choroidal neovascularization are common causes of visual loss. Description of the case: A 22 years old female patient presented with a 3-month history of painless, progressive decreasing vision ( $R E>L E)$ and metamorphopsia in her both eyes. She was previously diagnosed and treated for multifocal choroiditis 6 months ago, in one other center. Complete eye examination, fluoresceine angiography and OCT revealed the diagnosis of choroidal neovascular membrane (CNVM) as a result of Multifocal Choroiditis. The patient was treated in her both eyes with one combined intravitreal injection of Avastin $(1.25 \mathrm{mg} / 0.05 \mathrm{ml}) /$ Triamcinolon $(4 \mathrm{mg} / 0.1 \mathrm{ml})$, and 3 consecutive (every 4 weeks) intravitreal injections of Avastin (1.25 mg/0.05 ml). A close follow-up period of 11 months was completed. Conclusion: We reported a patient suffering from choroidal neovascular membrane as a result of multifocal choroiditis, with both eyes treated with one combined intravitreal injection of Avastin $(1.25 \mathrm{mg} / 0.05 \mathrm{ml}) /$ Triamcinolon $(4 \mathrm{mg} / 0.1 \mathrm{ml})$, and 3 consecutive (every 4 weeks) intravitreal injections of Avastin $(1.25 \mathrm{mg} / 0.05 \mathrm{ml})$. The treatment resulted safe and effective in increasing the visual acuity (LE $>R E)$ and improving the central retinal thickness. No vision threatening complication was noticed.
\end{abstract}

Keywords: Multifocal choroiditis, choroidal neovascular membrane, treatment

\section{Introduction}

Since the initial description of the disease by Nozik and Dorsch in 1973, hundreds of patients have been reported in the literature with multifocal choroiditis and panuveitis ${ }^{1}$.The disease affects otherwise healthy young patients in their third decade (average age, $34 \mathrm{y}$; range, 6-74 y), with an incidence of bilateral involvement of $80 \%{ }^{2} \mathrm{~A}$ moderate racial and gender predisposition exists, with approximately $66 \%$ of patients being white and $80 \%$ of patients being female. ${ }^{2}$ As well, myopia is present in more than $85 \%$ of these individuals. Cystoid macular edema, subretinal fibrosis, and choroidal neovascularization are common causes of visual loss. The incidence of choroidal neovascular membrane formation varies from $25-40 \% .^{2-3}$

\section{Case Report}

A 22 years old female patient presented with a 3-month history of painless, progressive decreasing vision (RE > LE) and metamorphopsia in her both eyes. She was previously diagnosed and treated for multifocal choroiditis 6 months ago with systemic steroids, in one other center (negative FTA-ABS, PPD, HLA-A29 negative and normal ACE levels and chest $\mathrm{X}$-ray). Complete eye examination, FFA and OCT revealed the diagnosis of choroidal neovascular membrane (CNVM) as a result of Multifocal Choroiditis. Anterior chamber was quiet and mild vitreous reaction (cells) was noticed. Best corrected visual acuity (BCVA) was 20/200 and $6 / 20$ in respectively her right and left eye (both eyes -3.0 sph. D). The central retinal thickness (CRT) was respectively $395 \mu \mathrm{m}$ and $340 \mu \mathrm{m}$. The patient was treated with one combined intravitreal injection of Avastin $(1.25 \mathrm{mg} / 0.05 \mathrm{ml})$ / Triamcinolon (4 $\mathrm{mg} / 0.1 \mathrm{ml})$, and 3 consecutive (every 4 weeks) intravitreal injections of Avastin $(1.25 \mathrm{mg} / 0.05 \mathrm{ml})$. A close follow-up period of 11 months was completed. The BCVA was $60 / 200$ and 12/20; CRT was 231 and $236 \mu \mathrm{m}$ after the first month of the follow-up. The BCVA was 60/200 and 18/20; CRT was reduced in 189 and $174 \mu \mathrm{m}$ respectively in the $5^{\text {th }}$ month after treatment. In the last visit (month 11) the vision remained stable at 60/200 and 18/20 and the CRT was 236 and $195 \mu \mathrm{m}$. No vision threatening complication was noticed.

\section{Discussion}

Management of choroidal neovascularization, a poor prognostic sign in multifocal choroiditis, can be difficult as the best treatment is yet to be determined. The current treatment options include periocular, intraocular, or oral corticosteroids; laser photocoagulation; photodynamic therapy ${ }^{4}$; and, most recently, anti-VEGF therapy.

As multifocal choroiditis is supposed to be an inflammatory disease, we thought that the combination of one antiinflammatory agent (triamcinolone) with one anti-VEGF (bevacizumab) drug would be the best treatment regimen for this case. This combination resulted in the functional and anatomical improvement which lasted for all the follow-up period.

\section{Conflict of interest}

The author declares that there is no conflict of interest.

\section{References}

[1] Nozik RA, Dorsch W. A new chorioretinopathy associated with anterior uveitis. Am J Ophthalmol. 1973 Nov. 76(5):758-62.

[2] Quillen DA, Davis JB, Gottlieb JL, et al. The white dot syndromes. Am J Ophthalmol. 2004 Mar. 137(3):538-50.

[3] Krill AE, Archer D. Choroidal neovascularization in multifocal (presumed histoplasmin) choroiditis. Arch Ophthalmol. 1970 Nov. 84(5):595-604. 


\title{
International Journal of Science and Research (IJSR) \\ ISSN (Online): 2319-7064 \\ Index Copernicus Value (2013): 6.14 | Impact Factor (2015): 6.391
}

[4] Spaide RF, Freund KB, Slakter J, Sorenson J, Yannuzzi LA. Treatment of subfoveal choroidal neovascularization associated with multifocal choroiditis and panuveitis with photodynamic therapy. Retina 2003;22(5):545-549.
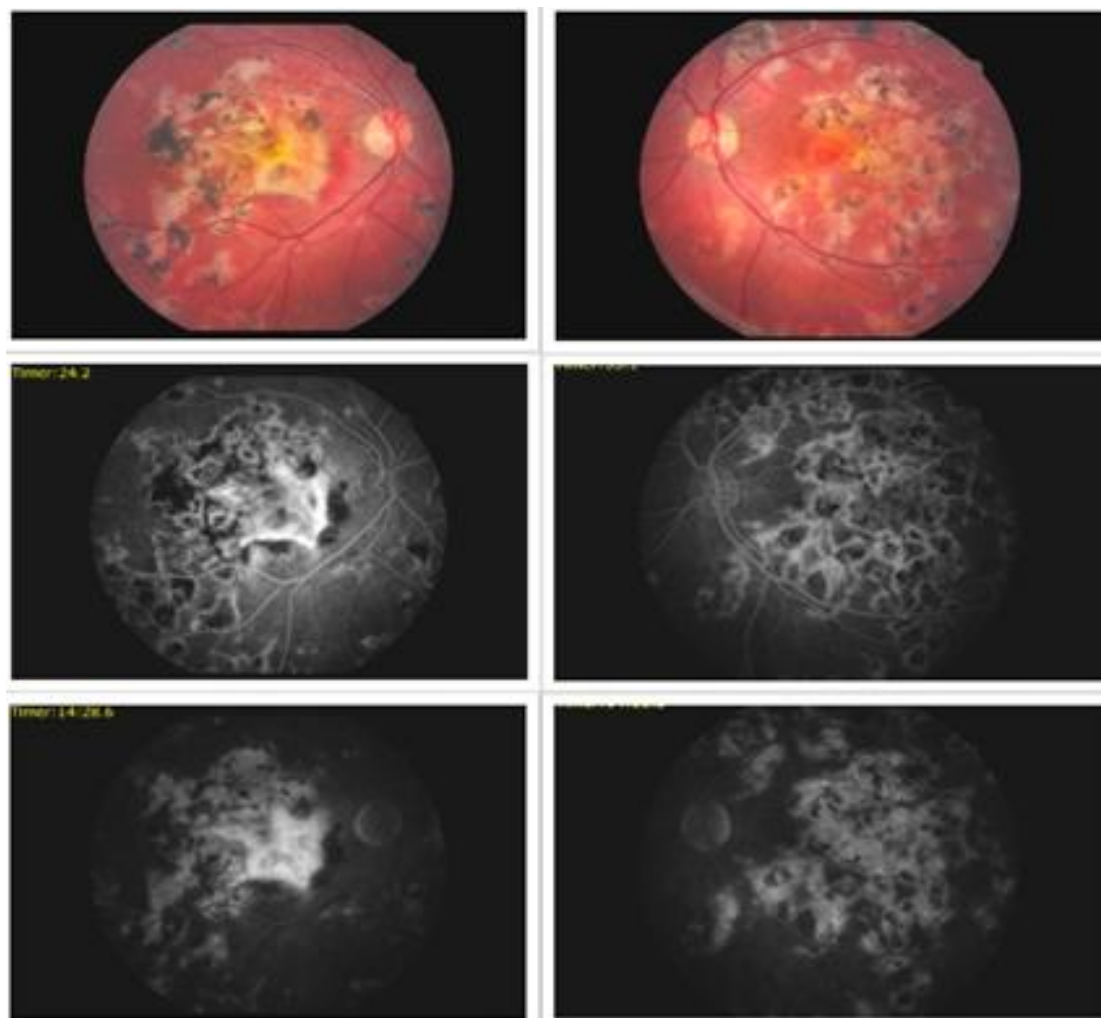

Picture 1: Fluoresceine Angiography before treatment (both eyes).
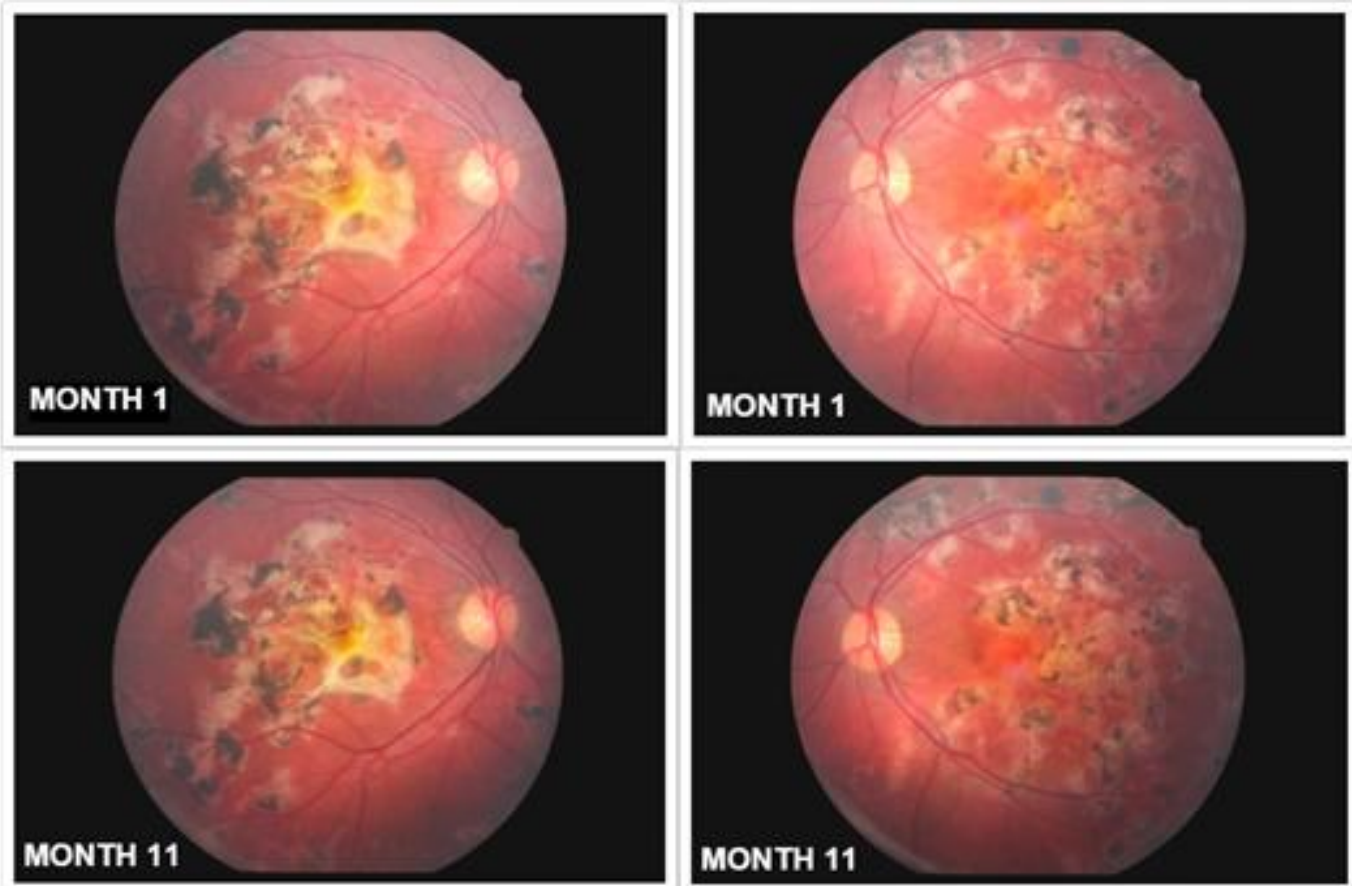

Picture 2: Fundus photography on month 1 and 11 after treatment.

Volume 5 Issue 5, May 2016

\author{
www.ijsr.net
}


International Journal of Science and Research (IJSR)

ISSN (Online): 2319-7064

Index Copernicus Value (2013): 6.14 | Impact Factor (2015): 6.391
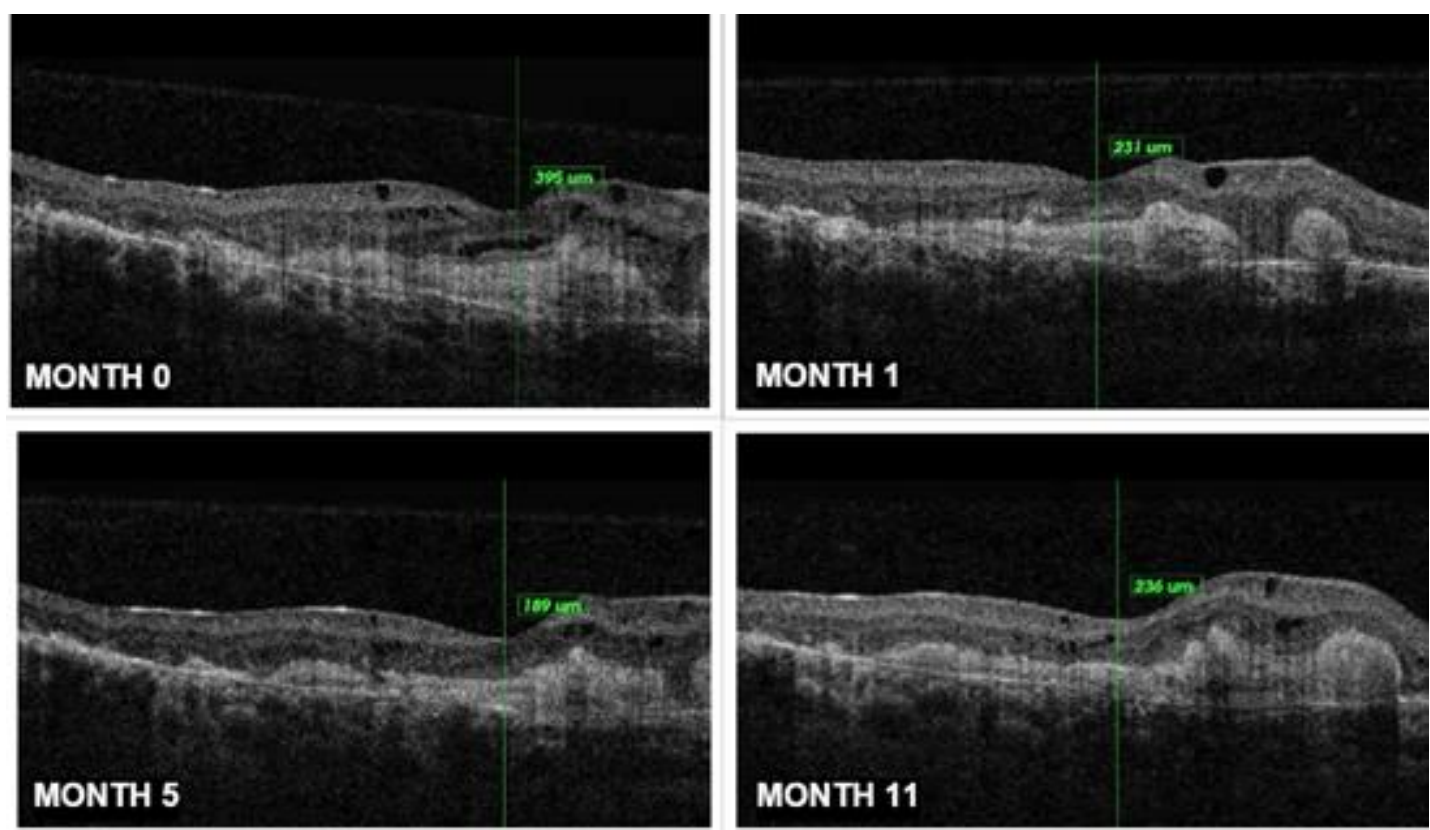

Picture 3: Right eye OCT images before treatment and during follow-up period.
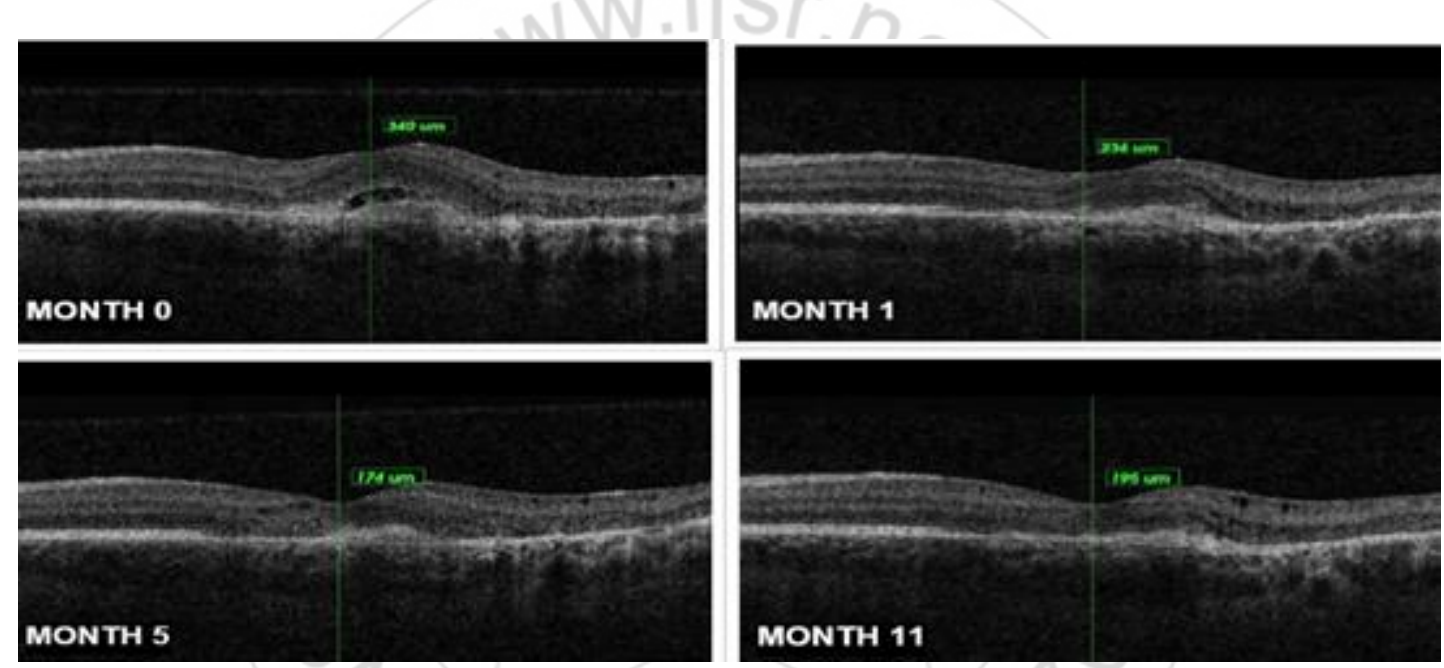

Picture 4: Left eye OCT images before treatment and during follow-up period.

Volume 5 Issue 5, May 2016

www.ijsr.net

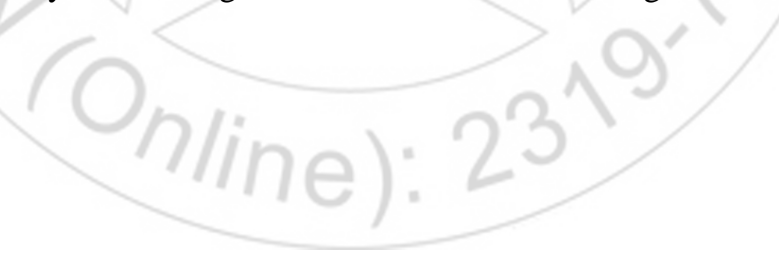

